\title{
Memórias de leitura, lugar de leitor e conhecimento na formação inicial de docentes
}

\author{
M árcia D resch*, Tatiana Bolívar Lebedeff* ${ }^{* *}$ Adriana D ickel***
}

Resumo: Estetrabalho tem por objetivo analisar, atravésdamemória discursiva, as experiências deleitura dealunos do curso de Letraseo impacto dessas experiências no processo deformação inicial. Asmemórias são resgatadas através da técnica degrupo focal eanalisadas à luz da Análise do $D$ iscurso. Propomos discutir a relação entreas experiências deleitura dealunos do curso de Letras durantesuaformação escolar eo modo como seenunciam como suje tosleitoresno curso superior. O s dados coletados revelam vínculos com a escrita, ora muito densos e afetivos, geralmente associadosà primeira infância eàfamília, ora de desencanto eaversão, relacionados à escola. N a universidade predomina uma postura deval orização erespeito para com a escrita, ligada a um comportamento crítico em relação a sua formação escolar eautocrítico enquanto leitor universitário.

Palavras-chave: leitura; memória; subjetividade; formação docente

Reading memories, the reader's place and knowledge in the initial teacher education programs

Abstract: Thiswork aimsto analyze, through discursivememory, the reading experiencesfrom Language Teaching course coursestudents and theimpact of these experiences on their initial teaching program. M emories are recollected through focus group technique and analyzed in light of Speech Analysis. We propose to discuss the relation among the Language Teaching coursestudents' reading experiences and theway they consider themselves as reading subjects. The collected data reveal bonds with the writing, which are sometimes affective, generally associated with their first childhood and families, and sometimesdisillusioned related to school. In university a position of valueand respect towards writing is predominant and it islinked to an attitudeof criticism concerning their school background and to an attitude of self-criticism as a university reader.

Key words: reading, memory; subjectivity; teacher education.

* Professora do Curso de Letras da Universidade Federal de Pelotas (UFPel), RS, Brasil. dreschm@gmail.com

** Professora da Área de Educação da U FPel, RS, Brasil. tblebedeff@ gmail.com

*** Professora do Curso de Pedagogia e do Programa de Pós-Graduação em Educação da Universidade de Passo Fundo (UPF), RS, Brasil. dickel@ upf.br 


\section{Introdução}

N este artigo, abordaremos a relação entre as experiências de leitura de estudantes do curso de Letras durante sua formação escolar e o modo como eles se enunciam como sujeitos leitores no contexto do Ensino Superior. Entendemos que o comportamento em relação à leitura condiciona sobremaneira não somente a formação profissional desses estudantes, mas também, posteriormente, a atividade docente, uma vez que se trata de uma das faces de sua relação com o conhecimento.

A questão da leitura na universidade - frequentemente identificada como um problema herdado da formação fundamental e média - está ligada às histórias de leitura e à forma como cada um, ao longo de suas experiências, relaciona-se com a escrita. 0 s dados revelam vínculos com a escrita ora muito densos e afetivos, neste caso associados à primeira infância e à família, ora de desencanto e aversão, geralmente relacionados à escola. $\mathrm{N}$ a universidade, predomina uma postura de valorização e respeito para com a escrita, ligada a um comportamento crítico em relação a sua formação escolar e autocrítico enquanto leitor universitário.

A coleta de dados foi conduzida pela técnica de grupo focal, a qual, segundo Iervolino e Pelicioni (2001), consiste na interação entre participantes e pesquisador, voltados para o entendimento de diferentes percepções e atitudes acerca de um fato, prática, produto ou serviço; e fundamenta-se na tendência humana de formar opiniões e assumir atitudes, quando diante de outros indivíduos. Foram convidados a participar da pesquisa onze alunos do segundo semestre do curso de Letras da Universidade Federal do Pampa, oferecido no campus de Bagé, município do Rio Grande do Sul, selecionados em virtude da frequente participação oral em aula. 0 s encontros ocorreram no final do segundo semestre letivo de 2008 e foram videogravados, sendo que o primeiro deles computou duas horas e vinte minutos e o segundo, uma hora e quarenta minutos. Os participantes, cujos nomes foram mantidos em sigilo, leram e assinaram um termo de consentimento livre e esclarecido. Participaram do primeiro encontro cinco estudantes, quatro moças e um rapaz, e, do segundo, três moças. 0 tema de discussão era "memórias de leitura", encaminhado pela moderadora do grupo por diferentes trajetos mnêmicos, ora memórias de leitura na família, ora na escola, dependendo das disposições dos participantes.

Iniciaremos nossas considerações pelas memórias de leitura constituídas na família, para, a seguir, abordar o que se verificou na escola, finalizando com a reflexão sobre a construção do sujeito leitor no curso de Letras. Essa identidade de sujeito-leitor-universitário é formada pelo atravessamento de diferentes for- 
mações discursivas e não pode ser compreendida como permanente. Também ela está sujeita à pressão e em constante mudança, à medida que os sujeitos entram em contato com outros discursos ou mesmo reelaboram suas lembranças. D isso decorre o caráter histórico dessa constituição, uma vez que, em que pese 0 olhar de cada um sobre sua própria história de leitura, estamos falando de identidades sociais, construídas, sobretudo, na família e na escola, durante a infância e a adolescência dos sujeitos, agora, universitários.

\section{O s primeiros contatos com a escrita}

Aprender a ler e a escrever, conforme Soares (2002), traz inúmeras consequências para o indivíduo, influenciando dimensões sociais, psíquicas, políticas, cognitivas, linguísticas e, inclusive, econômicas. Segundo a autora, o impacto dessas mudanças sobre o sujeito - a apropriação da leitura e da escrita e a incorporação das práticas sociais que as demandam - denomina-se letramento. Trata-se, portanto, de um conjunto de práticas sociais ligadas à leitura e à escrita com as quais os sujeitos se envolvem no seu contexto social.

M artins (2003) sustenta que "letrar" significa inserir a criança nos diferentes usos que a sociedade faz da escrita. Essa inserção ocorre quando a criança interage com práticas de letramento presentes no seu contexto: os pais leem para ela, a mãe faz anotações, os rótulos indicam produtos idênticos, reconhecidos nas prateleiras dos supermercados e na cozinha da casa. Soares (2002, p. 27) aponta que, para entrar nesse universo, é necessário "compreender, inserirse, avaliar, apreciar a escrita e a leitura", isto é, a criança precisa buscar um jornal para ler, frequentar revisteiras, livrarias e, com esse convívio efetivo com a leitura, apropriar-se do sistema de escrita. Terzi (1995), ao argumentar sobre a influência que um ambiente familiar rico em eventos de letramento oferece ao desenvolvimento inicial da leitura, defende a exposição constante da criança préescolar à leitura de livros infantis e salienta que, com isso, promove-se uma expansão do conhecimento não somente sobre as histórias e sua estrutura textual, mas também sobre a própria escrita.

Segundo Abramovich (2001), o primeiro contato da criança com o texto escrito é feito através da voz da mãe, do pai ou dos avós, os quais oralizam contos de fada, trechos da Bíblia, passagens de livros, poemas sonoros, etc. Para a autora, ler histórias para crianças, além de suscitar o imaginário e emoções como tristeza, raiva, alegria, insegurança, é uma possibilidade que a elas se oferece de descobrir mundos nos quais os conflitos, os impasses, os problemas são enfrentados e podem ser resolvidos por seus personagens; nos quais podem ser descobertos lugares, tempos, costumes, jeitos de vestir e viver, distintos daqueles que seus olhares se habituaram a ver. 
Bettelheim (1980) defende que as histórias enriquecem a experiência de vida da criança e ajudam-na a entender a si própria, a orientar-se em busca de soluções para os seus problemas, pois, sutilmente, oferecem sugestões para que ela lide construtivamente com experiências internas. Em especial, os contos defada, acrescenta 0 autor, dirigem a criança para a descoberta de sua identidade, além de sugerirem experiências que são necessárias ao desenvolvimento de seu caráter.

N esse sentido, M orais (1996) ressalta que a audição de leitura de livros feita por outras pessoas teria uma tripla função: cognitiva, linguística e afetiva. No plano afetivo, a criança descobre o universo da leitura pela voz, plena de entonação e de significação, daqueles em quem ela tem mais confiança e com quem se identifica. N o nível linguístico, a audição de livros permite esclarecer um conjunto muito variado de relações entre a linguagem escrita e a linguagem falada: 0 sentido da leitura, as fronteiras entre as palavras, a relação entre o comprimento das palavras faladas e 0 das palavras escritas, a recorrência das letras e dos sons, as correspondências letra-som, os sinais de pontuação, etc. Essa audição permite à criança aumentar e estruturar seu repertório de palavras e desenvolver estruturas sintáticas e textuais mais complexas. A criança habitua-se a parafrasear, a utilizar figuras de estilo, a explicitar sua compreensão. Com efeito, os conhecimentos linguísticos adquiridos durante a audição de histórias proporcionam à criança um trunfo considerável para enfrentar, já na escola, uma leitura progressivamente mais sofisticada. Já no âmbito cognitivo, possibilita à criança conhecimentos que a conversação sobre outras atividades cotidianas não favorece, uma vez que cria condições para a emergência de associações esclarecedoras da experiência dos outros e de si própria. M ais importante ainda, talvez, pela própria estrutura da história contada, pelas questões e pelos comentários que sugere, pelos resumos que provoca, ela ensina a compreender melhor os fatos, a organizar e reter a informação, a melhor elaborar os roteiros e os esquemas mentais. 0 exposto nos permite dizer que, sendo um fenômeno de linguagem e uma experiência cultural (C oelho, 2000), a literatura é fundamental à formação do indivíduo e uma das principais formas pelas quais as crianças recebem a herança e a tradição cultural e interagem com elas.

Para além do que até então recuperamos, existe uma diversidade de estudos sobre 0 impacto das práticas letradas familiares na aprendizagem da leitura e da escrita nos primeiros anos de escolarização. Purcell-Gates (2004) indica que: a) as crianças aprendem em suas casas muitos conceitos, habilidades, atitudes e condutas importantes para 0 desenvolvimento da leitura e da escrita, quando participam de momentos de letramento que surgem espontaneamente; b) muitos desses conceitos, habilidades e condutas são os que posteriormente vão ser desenvolvidos na escola; c) os programas de formação de leitores que envolvem as famílias, ensinando estratégias específicas de aquisição de lei- 
tura e escrita a serem aplicadas com as crianças, evidenciam melhorias escolares dos alunos.

Com relação à opção profissional, Bueno, Souza e Belo (2009) perceberam que, entre as 152 professoras do município de São Paulo, as práticas de leitura familiares foram de extrema importância na sua escolha pela docência, tanto entre aquelas que provinham de ambientes mais favorecidos economicamente como entre as que vieram de contextos desprivilegiados. Apesar de os participantes do grupo focal não relacionarem diretamente as memórias de leituras familiares com sua opção profissional, é interessante notar a carga afetiva (Sequência 1) presente nos relatos de memórias dos eventos de letramento e dos diferentes suportes de textos disponibilizados pelas famílias.

Sequência 1

Ah, eu tinha a caixinha dosclássicos, quea gentetinha quando era pequena. U ma vez eu nem tava em casa efoi engraçado, porqueo pai mesmo comprou, o pai ea mãe, equeera uma caixinha com os clássicos, aaa... a Branca deN eve, A Bela ea Fera, 0 Corcunda de $\mathrm{N}$ otredame, com os clássicos mesmo, só que uma versão menorzinha, maiscompacta, numa caixinha queera um baú, um bauzinho queabria etocava uma musiquinha, eera todo ilustrado, a coisa maisfofinha, até a capa do livro, não era uma capa dura, era emborrachadinha, toda bonitinha.... Então, já dava vontadedeler só pela beleza queera a caixinha, né?É engraçado, eu sempretivemuito incentivo pra ler em casa, o pai atéquenão lê muito, masa mãelêmuito, sempreleu muito. Então, lá em casa, os livrosespí ritasprinci palmente, eu atélivro espírita não leio muito, dependendo do romanceatéleio. Violetas najanela étri bonito.

Todos os estudantes componentes do grupo focal mencionaram a participação ativa da família na sua formação de leitores, com exceção de uma aluna cuja família, segundo ela, nunca incentivou nem valorizou a leitura. Esse relato (Sequência 2) chama a atenção pelo fato de fazer irromper uma posição contraditória no interior da formação discursiva universitária, para a qual a leitura se reveste de uma importância secular. Admitir vir de uma família cujos pais não atribuíam a si a responsabilidade da iniciação à leitura propõe um movimento à contracorrente, uma fala que desliza e vai de encontro ao discurso de glamourização da leitura, desvelando brechas de uma formação discursiva aparentemente composta de saberes unânimes e que acusa a ruptura desse discurso.

Sequência2

$\mathrm{N}$ ada... M eu pai nem sefala... M inha mãeatétem livrosespíritas, assim, masela... N ão tinha aquela coisa dechegar em casa ever 
meuspaislendo... U ma vez atéconversei sobreisso com des, maseles falaram quenada a ver, quese eu ti vesseinteresse eu ia procurar, maseu já discordo um pouco, porqueeu acho quesjá não tem na escola, não tem em casa... sei lá senão achavam importante, ou... isso.

A fala, em tom hesitante e resignado, expõe o conflito de saberes, à medida que a filha assume posição que questiona o procedimento dos pais, bem como a explicação dada por eles, que devolve a ela e à escola uma responsabilidade a eles imputada. Talvez, se os universitários integrantes do grupo focal fossem oriundos de outros cursos, essa experiência e, portanto, relatos como esse fossem recorrentes. Já aos estudantes do C urso de Letras, cujo compromisso com a leitura tem caráter mais formal, não é facultado dizer que não gostam de ler ou que não estão acostumados a ler. Imersos nessas condições de produção, é perceptível, nos relatos, o esforço para incorporar a leitura à sua história de vida, tornando-a desde sempre parte dessa trajetória.

\section{Ler é viver e a experiência escolar de leitura}

0 propósito de trabalhar com memórias de leitura assume dimensão maior do que a reunião de reminiscências de alunos universitários, uma vez que as enunciações manifestas fazem parte da rede de formulações que se instaura a partir do contato do sujeito com o mundo da escrita, como vimos acima, organizado de forma mais sistemática no período escolar. Para iniciarmos esta reflexão, cumpre o esclarecimento do que estamos chamando de memória e qual a sua relação com as lembranças trazidas pelos alunos.

A noção de memória na Análise do Discurso é desenvolvida primeiramente por Courtine (1981). Ao ressaltar que a memória não equivale à memorização psicológica, 0 autor demarca desde logo o terreno sobre 0 qual a Análise do D iscurso vai transitar. A memória é, então, entendida como memória discursiva e concerne à existência histórica do enunciado no seio das práticas discursivas (Courtine, 1981, p. 52-53). Trata-se, portanto, de uma memória coletiva, construída nas próprias práticas discursivas e que não se apresenta de forma cronológica e regular, mas tramada pelos processos históricos e densa de significações. Conforme Courtine (1981, p. 51), a memória irrompe na atualidade do acontecimento; assim, quando falamos de memória discursiva, estamos pensando numa imensa rede de formulações tecidas na história, o que coloca a repetição como um dos modos de a história aparecer no discurso. Vista dessa forma, a memória que emerge dos discursos dos alunos, para além da experiência pessoal de cada um, faz parte de um conjunto de práticas sociais que discursivizam a leitura em nossa sociedade. 
Para Guimarães (2000, p. 30), a língua funciona movimentada por uma memória de sentidos. Essa memória de sentidos coloca-nos perante uma perspectiva histórica. N ão daquela história linear, intercalada por marcos, mas uma noção de história constitutiva, na qual os sentidos se agregam e compõem 0 tecido discursivo. Todo discurso vem constituído, tramado pela história, que age incessantemente na língua, e, no discurso sobre leitura, a trama é tão antiga quanto a história do Brasil.

Já no início da colonização, alavancados pelo projeto educacional de catequização do novo mundo, os jesuítas lançaram as condições para a consolidação de uma prática pedagógica que teve forte contribuição para a formação da consciência de nação e de língua impostas. Fracassados os propósitos jesuíticos, com a sua expulsão no século XVIII, a educação, durante o Império e muito depois de o Brasil ter-se tornado República, era privilégio de poucos. É a partir da década de 1970 que a escola pública amplia seu alcance e passa a atender um maior número de crianças e jovens. É também quando se intensifica a atividade do $M$ ovimento Brasileiro de Alfabetização ( $M$ obral), criado ao final dos anos 1960. Dadas as condições mínimas para o desenvolvimento de uma sociedade leitora, o discurso sobre a importância da leitura propaga-se. A este discurso fundador de uma população letrada que atribui status à prática de leitura, promovido especialmente no espaço escolar, acrescentem-se campanhas que há décadas circulam na mídia e em cujas chamadas circundam enunciados como "ler é bom demais", "ler é uma viagem"; "ler é o melhor exercício para a mente", "ler é muito bom", "ler é transformar"; "ler abre a cabeça", "ler é fundamental", "ler é viver"... É nesse imaginário de leitura que se constitui o lugar de onde falam os estudantes.

Curiosamente, não é o discurso ufanista nem apológico sobre a leitura que ouvimos no grupo focal; pelo contrário, as memórias de leitura, durante a formação escolar, ou têm um caráter muito afetivo (Sequência 3), ou remetem a experiências negativas (Sequências 4 e 5).

\section{Sequência 3}

$\mathrm{Na}$ 3a ou 4ạ série, eu tô melembrando agora... tinha a hora do conto. Com a tia Rosinha, atéhojeela trabal ha lá na escola... A té que na 3 a teve o projeto do livro, né? A gente tinha toda a semana, que ela sentava com toda a turminha... ela lia o livro pra gente, assim... a gentenão lia, masela lia, a gente conhecia uma história, falava um pouco da história... via o que gente tinha entendido, o quea gente tinha gostado... isso eu melembro... foram doisanos. 
Sequência 4

Eu fui ler mesmo depois, por minha conta, não por estímulo da escola, não houveabsolutamenteestímulo.

\section{Sequência 5 \\ Q uando introduzem oslivrosnosfalta bagagem... enão nosdão nenhuma contextualização, então al gunsatétu entendemais, ou- trosnão, masoutrosacabam traumatizando, tem pessoasquenun- ca leem mais esses livros porque não entendem e porque se traumatizaram com o Ensino M édio...}

As experiências narradas concentram-se no Ensino Fundamental e são bem pontuais - um aluno narra uma experiência da quarta série, outro da sétima, outro da oitava -, mas sobressai, mesmo no Ensino Fundamental, a ideia de que 0 trabalho de leitura desenvolvido pela escola ficou aquém da expectativa deles. D escrevem, por exemplo, atividades de cópias de livros ou mesmo a inexistência de práticas pedagógicas de leitura.

Sequência 6

Tinha que copiar do livro que nem a FU LAN A, muito copiei, copie muito do livro.

\section{Sequência 7}

Só na 8a série, como eu tinha falado, quetevea ficha deleitura, assim, massó aquela vez.... Eu meobrigava a ler porquetinha a nota.

Enquanto a lembrança do trabalho no Ensino Fundamental é marcada por vazios, a do Ensino $M$ édio está bem presente, inclusive porque nesse nível a disciplina de Literatura faz parte da grade curricular (Sequências 8 e 9). M as isso não significa que as referências se tornem mais positivas...

Sequência 8

[...] vamosdizer assim, queleitura équasezerono Ensino Fundamental eaí tu chega no Ensino M édio teobrigam a ler duzentas coisas... Como équetu vai gostar deler? Como équetu vai gostar deler alguma coisa?Tu sai do nada... sai de um escorregador de gi letepara uma piscina deálcool! Aí setorna meio estranho...

\section{Sequência 9}

E tu chega no 30 ano quetem vestibular, quetu tem quesaber fazer uma boa interpretação, tu não sabel Por isso queasnotasficam tri baixas... É um baque, tu nunca leu, semprelia tri folgadão... aí chega no $3^{\circ} . .$. 
O s relatos de uma das alunas sempre destoavam dos demais. I sso porque sua experiência escolar de leitura e escrita tinha sido muito rica (Sequência 10).

Sequência 10
Q uem cresceem colégio construtivista o incenti vo à le tura, eessas
coisas, escrita, a gente fazia textos, redação, etc., desdea 1a série,
mermo quetu escrevesseum montedeporcaria. N em sei, nem lembro
o que escrevia, mas a gente adorava escrever pági nas e pági nas
porque achava que estava arrasando, sabe? E a gentefazia isso e
todosescrevem muito bem etodos são óti mosalunos. E tem aquela
coisa, quenão sei seécoincidência, masosami gosqueeu conheço
quecresceram comigo no colégio construtivista elestêm, amam,
amam ler!

A aluna vincula seu apego pela leitura, bem como o de seus amigos, à proposta pedagógica da escola que frequentou, diferente das referidas pelos demais participantes do grupo, que tinham práticas pedagógicas interpretadas, por eles mesmos, como tradicionais. Esse fragmento permite expor o nosso entendimento de que significativas e eficientes práticas de leitura na escola são importantes influências na formação do leitor e de que, não obstante a oposição que ele suscita entre escola tradicional e construtivista, podem tais práticas ser realizadas em todas as perspectivas de ensino.

\section{D iscutindo a leitura no meio acadêmico: 0 discurso agregado}

A partir do corpus, duas questões mobilizam-nos para pensar a leitura na universidade. A primeira diz respeito à visão de texto e de leitura que perpassa os discursos, visão essa que privilegia fundamentalmente o texto literário, que, por sua vez, é apresentado com respeito, admiração e também com grande cautela. Como vimos anteriormente, segundo os alunos, a escola falhou no ensino de leitura; assim, encontram-se diante de um objeto que lhes apresenta mistérios e surpresas, sentidos que eles acreditam lá estar e que receiam não estar vendo.

Se a importância da leitura é pressuposta no meio acadêmico, inúmeras vezes nos deparamos com manifestações de professores de cursos das mais variadas áreas, preocupados com a dificuldade de interpretação de seus alunos. De parte dos alunos, exteriorizam a dificuldade de compreensão dos textos indicados por seus professores. Essas manifestações assinalam o distanciamento e a sensação de impenetrabilidade no texto e podem ser compreendidas a partir da análise do processo discursivo de constituição do leitor. No grupo pesquisado, os sujeitos colocam-se numa relação de subserviência ao texto, cujos sentidos, às vezes simples (Sequência 11), não são capazes de decifrar. As Sequências 11, 
12 e 13 referem a falha da escola em ensinar como se lê, a interpretar e enxergar os sentidos para além do explícito. A descoberta, na universidade, de que os sentidos não são transparentes produz uma relação de insegurança diante da língua, a ser enfrentada com parcos recursos pelos estudantes.

\section{Sequência 11}

É a vel ha questão, o texto émal trabalhado na escola, senão tem a base, mostrando como selê... na própria faculdade, a gentechega, muitasvezes, sem saber lex... sevai pegar um texto literário econse guir passar do quetá dito... enxergar ascoisas, mascomo équeeu não vi isso, tão simples..

\section{Sequência 12}

Osdadosbás cosdeinterpretaçãoeascoisasquepodem ettar por trás do livro, ninguém teexplica. [...]

\section{Sequência 13}

0 quefalta écomo ler, éexplicar isso pra gente...Trabalhar com textosclássicospra gentecomeçar a aprender eabrir a visão... poesia smples... tu não vai ler somentejornal, tu vaisler algo maisrebus cado... precisa saber ler... [...]

$\mathrm{N}$ ote-se que, se o texto literário, por um lado, é lembrado como o que oculta os sentidos, por outro, é o que permite, pela sua complexidade, "abrir a visão". I gualmente se percebe 0 valor atribuído à leitura e o desejo de dominar um conhecimento que, contraditoriamente, subjuga e seduz.

A segunda questão coloca-nos a pensar sobre de que forma saberes do curso de Letras perpassam o discurso desses sujeitos, ou seja, como o discurso da área ressoa na fala dos alunos e vem constituir a crítica ao trabalho com leitura realizado pela escola. Conforme dito anteriormente, os participantes do grupo estavam concluindo o segundo semestre do curso; portanto, conviviam há praticamente um ano com o discurso acadêmico sobre leitura, o que lhes permitia agregar elementos outros à análise de sua formação escolar, além daqueles que circulam comumente entre acadêmicos de outras áreas, os quais geralmente estão centrados na inaptidão individual para a leitura e para a escrita ou na sensação de impotência perante a complexidade do texto/conhecimento acadêmico.

Sequência 14

$\mathrm{N}$ ão tevereal mente, a única coisa quemelembro assim ... tinha unslivros, né... N ão sei como équesediz quando o livro é..., tem aquelelivro certo, o livro escolhido, então todostinham aquelelivro 
deportuguês. $E$ eu não sei por quesea gente ficava com olivro a gente tinha que copiar... E daí tinha a interpretação, não era interpretação, exercíciosqueeram completamentededecodificação, assim, sabe?

\section{Sequência 15 \\ Cópia de livro di dático, ai, as questões são de interpretação ou decodificação? Ah, a maioria das questões era de decodificação, coisasassim, sabe, no texto tinha duasirmãs... quantasirmãsti- nha no texto? Coisasassim, sabe? Então tu tá acostumado com isso, quando tem quepensar, tu dizer o queeu acho... É uma coisa quetu perdeo chão.}

Afora os aspectos já comentados anteriormente, chamam-nos a atenção alguns enunciados: "E daí tinha a interpretação, não era interpretação, exercícios que eram completamente de decodificação, assim, sabe?"; "Ah, a maioria das questões era de decodificação, coisas assim, sabe, no texto tinha duas irmãs... quantas irmãs tinham no texto? Coisas assim, sabe?". N eles vemos operar um préconstruído próprio da formação discursiva da área de Letras, qual seja, de que a escola confunde interpretação com decodificação, privilegiando a atividade de decodificação, cuja complexidade é menor. Ao argumento o aluno agrega, ao final, um marcador de interação - assim, sabe? --, que, mais do que buscar a concordância do entrevistador e dos demais presentes, denota a heterogeneidade de que se reveste esse discurso, a presença marcada de um discurso do qual ele se apropriou para enunciar sua crítica. A expressão "assim, sabe?" marca o conhecimento da área e revela que é compartilhado, heterogê neo, pois, por excelência.

Segundo Pêcheux (1988, p. 52), a memória discursiva é aquilo que, diante de um texto que surge como conhecimento a ler, vem estabelecer os "implícitos" (os pré-construídos, elementos citados e relatados, discursos-transversos). O rlandi (1999, p. 64), ao aproximar a noção de memória à de interdiscurso, sustenta que a memória é o saber discursivo que faz com que, ao falarmos, nossas palavras façam sentido. Ela se constitui pelo já-dito que possibilita todo dizer. 0 encaixe desses elementos pré-construídos também é possível observar nas Sequências 16 e 17.

Sequência 16

$\mathrm{N}$ o Ensino Fundamental, por maisqueteapresentem textosnos livros didáticos, o maior interessequetem éteensinar gramática... Setu não desenvolveo ato da le tura, setu não desenvolveo ato de interpretar alguma coisa. D ificilmente.. 


\begin{abstract}
Sequência 17
A genteolha àsvezesetem um texto tri bom, quefaz parteda vida do aluno, queincentiva horrores $D$ aí, tu faz trêsperguntas quetu acha, na tua experiência, que tu pensa, não sei que, tá, agora esquece, aí aparece faça os exercíci os de acordo com o modelo acima... N ão adianta, só tá mascarando, ter o texto lindo ali... Vai seguir tendo portuguêscomo há 40 anosatrás...
\end{abstract}

A crítica, nas sequências acima, toma aqui outro viés de discussão que circula nos cursos de Letras: 0 ensino de gramática na escola. 0 aluno, ao comentar a sua percepção sobre o trabal ho com leitura, traz justamente a censura à predominância do ensino de gramática em detrimento do trabalho com o texto, 0 que, como ele diz, não desenvolve a leitura e a interpretação. É importante notar que ele assume uma posição no seu discurso, encobrindo o discursooutro ali encaixado. Pêcheux (1988, p. 173) explica esse encobrimento ao explicitar os dois esquecimentos dos quais o sujeito é acometido. 0 primeiro referese ao fato de o indivíduo ter a ilusão de ser a fonte de seu dizer, ou seja, o sujeito enuncia a crítica como se fosse sua, tomando para si a responsabilidade do dizer. 0 segundo preserva o espaço da enunciação em que o sujeito "seleciona" seu dizer, escolhendo o que pode e o que deve ser dito a partir de seu ato de interpretação, que, embora não plenamente consciente, distinguese do primeiro esquecimento por conter essa possibilidade de escolha dada numa zona pré-consciente. Conforme Courtine (1999), não há sujeito no interdiscurso, mas um lugar inominável; entretanto, diz ele, funcionam "posições de sujeito" que regulam o ato de enunciação - o interdiscurso fornece, na forma de citação, recitação ou pré-construído, os objetos do discurso nos quais a enunciação se sustenta e organiza a identificação enunciativa (marcas pessoais, tempo, aspecto, modalidade) na produção da formulação por um sujeito enunciador. D essa forma, acaba por diluir a memória (e 0 assujeitamento) e garante-se um "eu", um "aqui" e um "agora". N a enunciação estabelece-se uma relação imaginária entre 0 momento da enunciação e o domínio da memória. Courtine (1999), no rastro de Foucault (2000), chama isso de "rituais discursivos da continuidade", que, ao produzirem um corte temporal, ligam o passado à atualidade e ao futuro, promovendo uma anulação imaginária do processo histórico.

\title{
5. Considerações finais
}

A discussão no grupo focal evidenciou três momentos principais de registro de memórias de leitura: a leitura familiar, a leitura na escola e a leitura na universidade. A experiência familiar aparece, em sua maioria, ligada a situações 
estimulantes e prazerosas, e os relatos são acompanhados de grande carga afetiva. $\mathrm{N}$ a escola, identificamos dois momentos distintos: o Ensino Fundamental, marcado pela ausência de atividades; e o Ensino M édio, em que os alunos atualizam o discurso da leitura por obrigação e voltada para a avaliação e 0 vestibular. A síntese do processo escolar aparece quando os sujeitos chegam à universidade, olham para suas experiências de leitura e passam a questionar 0 trabal ho realizado e o próprio ensino de língua portuguesa na escola. $\mathrm{H}$ á alunos que chegam a enunciar que obras lidas na escola somente agora, na universidade, passaram a ser entendidas. Esse tipo de relato coloca em cena a questão da defasagem por eles percebida em sua própria formação, o que vai ao encontro do discurso que circula entre os docentes sobre a falta de proficiência em leitura dos estudantes.

A consciência de não atender à expectativa que a universidade tem em relação a um sujeito-leitor, situação esta justificada ora pelos hiatos da formação no Ensino Fundamental e M édio, ora pelo hermetismo e dificuldade que identificam nos textos que têm de ler no curso superior, pode contribuir com um olhar mais atento sobre esses alunos e sobre a sua formação profissional.

\section{Referências bibliográficas}

ABRAM OVICH , F. Literatura infantil. São Paulo: Scipione, 2001.

BETTELHEIM , B. A psicanálisedoscontosdefadas Rio dejaneiro: Paz eTerra, 1980.

BUEN O , B. O .; SO UZA, D .T.; BELLO , I. M . A leitura ea escrita deprofessorasfaceaosdesafios dosnovos letramentos. D isponível em: $\varangle$ www.anped.org.br/ reunioes/30 ra/trabalhos/gt08-3048int.pdf>. A cesso em: 11 out. 2009.

COELH O , N elly N . Literatura infantil. São Paulo: M oderna, 2000.

COURTINE, J-J. Analyse du discours politique. Langages- Larousse, Paris, n. 62, 1981.

COURTINE, J-J 0 chapéu de Clémentis. Tradução de M arne Rodrigues de Rodrigues. In: IN D U RSK Y, F.; FERREIRA, M . C. L. O smúltiplosterritórios da análise do discurso. Porto Alegre: Sagra Luzzatto, 1999. p. 15-22.

FO U CAU LT, M . A arqueologia do saber. Tradução de Luiz FelipeBaeta N eves. Rio de aneiro: ForenseU niversitária, 2000.

GUIM ARÃES, E. Semântica do acontecimento. Campinas, SP: Pontes, 2000.

IERVO LIN O , S. A.; PELICIO N I, M . C. F. A utilização do grupo focal como metodologia qual itativa na promoção da saúde. Revista Escola Enfermagem - USP, São Paulo, v. 35, n. 2, p. 115-21, jun. 2001.

MARTIN S, A. Alfabetização e letramento. Disponível em: বhttp://www. brazcubas.br/ professores/alice/download/texto2s4.doc>. Acesso em: 3 dez. 2003. 
M O RAIS, J. A artedeler. São Paulo: Unesp, 1996.

O RLAN D I, E. P. M aio de 1968: os silêncios da memória. In: ACH ARD , P. et al. Papel da memória. Tradução de JoséH orta N unes. C ampinas: Pontes, 1999. p. 59-67.

PÊCH EUX, M. Semântica e discurso: uma crítica à afirmação do óbvio. Tradução de Eni Pulcinelli O rlandi et al. Campinas, SP: Editora da U nicamp, 1988.

PURCELL-GAT ES, V. A alfabetização familiar: coordenação entre as aprendizagens da escola eas de casa. In:TEBEROSKY, A.; GALLART, M . S. Contextosdealfabetização inicial. Porto Alegre: Artmed, 2004.

SO ARES, M . Letramento: um tema em três gêneros. Belo H orizonte: Autêntica, 2002.

TERZI, S. A oralidadeea construção daleitura por crianças demeiosiletrados. In: KLEIM AN , A. (O rg.). O ssignificados do letramento. C ampinas: M ercado de Letras, 1995.

Recebido em 15 deoutubro de2010 eaprovado em 10 dedezembro de2010. 